\title{
Traições mediáticas: a brasilidade em Os Sertões $e$ Os Sertões no cinema
}

Valéria Rosito Ferreira I UFRJ

\begin{abstract}
Resumo: Este trabalho enfoca a figura do narrador como tradutor de alteridades dentro de um ideal de nação e de república no Brasil. Os Sertões de Euclydes da Cunha (1902) e Guerra de Canudos de Sergio Rezende (1997) integram o corpus sobre o qual ocorre a discussão do status da verdade, do estatuto de original e dos meios de tradução como produtores de significado e de traição. O gênero testemunhal é questionado em seu caráter ideológico tanto nos discursos sociológicos como modelos de mundo quanto em adaptações ficcionais e/ou cinéticas.

Palavras-chave: alteridade, nação, tradução.
\end{abstract}

\section{Introdução}

Este trabalho procura examinar alguns discursos sobre a alteridade dentro de uma subjetivação que se quer "brasileira" em dois textos principais: Os Sertôes de Euclydes da Cunha (1902) e Guerra de Canudos de Sergio Rezende (1997), este último realizado a propósito do centenário da campanha de Canudos. Privilegiamos aqui a discussão das condições históricas de produção do livro e da precarização da voz autoral como testemunha da Natureza, trafegando da 
mediação invisível para dimensões produtivas como narrador. O diálogo com seu análogo cinético justifica-se pelo nosso interesse em, ao aquilatar questões de tradução intermediática e diacrônica, contribuir, em última análise, para o entendimento da produção e da recepção contemporâneas de representações sociais em produtos culturais. O cotejo nos possibilita também examinar o status das trocas simbólicas nos dois extremos do século XX no Brasil, apontando para o cruzamento entre a crítica sociocultural e a estética de massa. Em outras palavras, procuraremos discutir por que meios e com que resultados a brasilidade é traduzida pelo testemunho jornalístico-socioantropológico e pela indústria cultural em versões finesseculares, (des)construída como identidade e alteridade na medida em que tais versões se deixam absorver por seus enunciados ou deles se afastam. Canalizaremos nossa atenção para as formas discursivas com que diferentes media produzem, através de recursos que lhes são imanentes, narrativas que constroem o Outro a partir de um descentramento do Mesmo. $\mathrm{Na}$ primeira obra, intriga-nos o despertar de uma alteridade que ensaia romper com os moldes, letras e tradições que forjavam uma "identidade" nacional impregnada de pretensões naturalistas - sem dobras e sem tensão. Interessanos o exame das condições discursivas que, então, como talvez ainda agora, reduzem a "novidade" republicana no Brasil não a uma "experiência" dialógica com o Outro, como reza a cartilha universal dos moldes modernos, mas a um travestimento do status quo, onde as pluralidades sejam imediatamente controladas pela força física ou pelo congelamento de suas falas, pois são estas prescritas de fora para dentro. Por fim, atrai-nos o olhar contemporâneo sobre a obra euclidiana na medida em que estaremos discutindo modos de tradução dentro de um espectro que propõe apreender um original (mundo como texto e texto como mundo) acrítica, literal, e ingenuamente ou dele se liberta, traindoo em uma certa medida pela utilização de meios próprios que, alterando o original, preservam com mais eficácia sua economia semiológica, redimindo-se no exato momento da deserção.

Das preliminares acima alinhavadas, o gênero "testemunhal" aflora problematizado tanto para saberes sociológicos como para saberes estéticos no sentido em que, já no momento de apreensão de seu objeto, a testemunha estremece como mediadora e passa a se incluir nas redes de saber/poder produtoras da "verdade", metamorfoseando-se, portanto, como narrador. A existência em si do objeto é redefinida a partir da valorização dos meios de tradução e da imaginação criativa. Desestabilizam-se também os modelos 
naturalistas de documentação, sejam estes verbais ou fotográficos/cinéticos, por um lado, e, por outro, substancia-se a crítica aos fundamentalismos científicos, culturais e estéticos da contemporaneidade. Pelas obras selecionadas, procuraremos então rastrear as traduções de brasilidade em media distintos e afastados por um século de histórias.

\section{Euclydes e os estranhos sertanejos}

- Os Zecks são todos 'beimlich.'- 'Heimlich'? O que
você entendepor heimlich?'-Bem, ... são como uma
fonte enterrada ou um açude seco. Não se pode
passar por ali sem ter sempre a sensação de que a
água vai brotar de novo.'- 'Oh, nós chamamos isso
'unheimlich'; vocês chamam 'beimlich'. Bem o que
faz você pensar que há algo secreto e suspeitoso
acerca dessa familia?

Gutzkow

O que mais nos interessa na elaboração teórica de Freud sobre a experiência do estranho é o modo pelo qual a palavra estranho (beimlich) em alemão é inclusiva de seu oposto, unheimlich. Como facilmente se percebe, além de a forma positiva da palavra ser investida por duplo registro - o que é conhecido, familiar e agradável contra o que está oculto, enterrado - sua forma, negativizada pela prefixação de un-, opõe-se ao primeiro sentido, voltando a enterrar o que é doméstico ou conhecido (FREUD, 1919: 283) É o Mesmo - sua própria imagem refletida - que lhe escapa, tornando-se o Outro - virtualidade e representação em estado puro.

A exemplo do panopticum dos meios de comunicação de massa contemporâneos, que tudo "escondem" por tudo "verem", a anatomização da exterioridade pela descrição de então seqüestra a fala do Outro, pois prescreve subjetividades a serem encenadas antes mesmo de o momento comunicativo se atualizar. Em Euclydes, tais rochas, plantas, homens e sociedades permanecem estáticos, como aquele que os olha, bastando que para que sua "verdade ontológica" aflore sejam todos revestidos de mais e mais letras. A perpetuação aos nossos dias da composição descritiva, criticada por Lukács em Narrar e Descrever, serve-nos ao duplo propósito de examinarmos os desdobramentos contemporâneos do fetichismo da realidade/verdade e de melhor fruirmos a singularidade das adversativas trazidas pela obra brasileira centenária ora discutida: 
No objetivismo de Zola o princípio de composição é dado pela unidade objetiva de um determinado campo que é escolhido como tema; a base da composição é propor-cionada pelo fato de que todos os principais momentos objetivos da realidade descrita sejam apresentados a cada vez de um ângulo diverso. O resultado é uma série de imagens estáticas de naturezas mortas, que só materialmente se ligam a elas: dispõem-se, segundo a lógica interna de cada uma, umas ao lado das outras, e não umas depois das outras, e muito menos umas derivadas das outras. (LUKÁCS: 85) (grifos acrescentados)

A crítica acima integraliza-se justamente pelo exame do pólo "subjetivo" como passível de semelhante reificação:

Não são muito maiores as possibilidades de variação oferecidas pelos romances que se inspiram na posição subjetivista. (...) E a oposição existente entre sujeito e mundo externo é de tal modo rígida e dura que não enseja qualquer dinâmica de relações mútuas. (...) E, deste modo, o subjetivismo extremado se aproxima, paradoxalmente, da materialidade inerte do objetivismo. (ibid: 86) (grifos acrescentados)

A manutenção da opção bio-sociológica produtora de "naturezas mortas" a despeito do crescente desconforto trazido pela vivência empírica do repórter como testemunha resulta no que entendemos ser a fantasmagoria de sua composição, que, sem romper com a ordem estabelecida, justapõe duas leituras para os signos dados, como podemos ver a seguir:

Prosigamos considerando directamente a figura original dos nossos patricios retardatarios. Isto sem methodo, despreten-ciosamente, evitando os garbosos neologismos ethnologicos.

Faltaram-nos, do mesmo passo, tempo e competencia para nos enveredarmos em phantasias psycho geometricas, que hoje se exaggeram num quasi materialismo philosophico, medindo o angulo facial, ou traçando a norma verticalis dos jagunços.

Se nos embaraçassemos nas imaginosas linhas dessa especie de topographia psiquica, talvez não os comprehendessemos melhor. Sejamos simples copistas. Reproduzamos intactas, todas as impressões, verdadeiras ou illusorias, que tivemos quando, de repente, acompa-nhando a celeridade de uma marcha militar, demos de frente, numa volta do sertão com aquelles desconhecidos singulares, que alli estão - abandonados - ha tres seculos. (CUNHA, 1933: 112-113) (grifos acrescentados) 
Notemos que se por um lado se descortina como histórica ("abandonados por três séculos") a linha para a compreensão do quadro social, por outro lado, "as fantasias etnográficas" são um "exagero", portanto distintas da proposta do autor em grau, não em qualidade. Propõe então uma investigação inicial fenomenológica pela qual impressões "verdadeiras ou ilusórias" pudessem ser reproduzidas, sem mediação. Os trechos que se seguem primam pela organi-zação em torno de contrastes - os "assaltos subitâneos" - contrastes estes que encontram sua correspondência no binômio verdade/ilusão proposto no enunciado.

O firmamento limpido arqueia-se alumiado ainda por um sol obscurecido de eclipse. (...) A temperatura cae em minutos, e, minutos depois, os tufões sacodem violenta-mente a terra. (...)

É um assalto subitâneo. (...)

E uma hora depois o sol irradia triumphalmente no ceu purissimo! (ibid: 74-75)

Onde estaria a verdade climática dos sertões uma vez que verdade e ilusão ligadas por "ou” são excludentes? No "firmamento límpido" ou nos "tufões?" Na passagem abaixo, descritiva agora do caráter do sertanejo, a "preguiça" visibilizada nos modos, na fala e na música sertaneja é ilusória, pois um "assalto subitâneo" também traz à luz a verdade oculta. Examinemo-la:

É o homem permanentemente fatigado.

Reflecte a preguiça invencível, a atonia muscular perenne, em tudo: na palavra remorada, no gesto contrafeito, no andar desaprumado, na cadencia langorosa das modinhas, na tendencia constante à immobilidade e à quietude.

Entretanto, toda esta apparencia de cansaço illude.

Nada é mais surprehendedor do que vê-la desappa-recer de improviso. (...) e da figura vulgar do tabaréo canhestro, reponta, inesperadamente, o aspecto dominador de um titan acobreado e potente, num desdobramento surprehendente de força e agilidade extraordinarias. (...)

Este contraste impõe-se ao mais leve exame. Revela-se a todo o momento, em todos os pormenores da vida sertaneja - caracterisado sempre pela intercadencia impressionadora entre extremos impulsos e apathias longas. (ibid: 115) (grifos acrescentados)

Em que lugar estará então a verdade da brasilidade se "raça" como categoria de identidade é circunscrita por signos permutáveis e enganadores 
que desafiam a ordem dos espelhos na apreensão do universo? Destaca-se uma dentre as réplicas do autor incluídas ao fim da edição de que nos valemos: exatamente a que responde à acusação de veicular idéias contraditórias a respeito da essência da nação brasileira, ora "a rocha viva da nossa raça", ora uma sociedade "sem unidade de raça":

Neste salto mortal de 616-70=546 páginas, é natural que se encontrem cousas disparatadas. Mas quem segue as considerações que alinhei acerca da nossa genesis, se comprehende que de facto não temos unidade de raça, admitte tambem que nos varios caldeamentos operados eu encontrei no typo sertanejo uma sub-categoria ethnica já formada (pag.108) liberta pélas condições historicas (pag.112) das exigencias de uma civilisação de emprestimo que lhe perturba-riam a constituição definitiva.

Quer isto dizer que neste composto indefinivel - o brazileiro - encontrei alguma cousa que é estavel, um ponto de resistencia recordando a molecula integrante das crystallisações iniciadas. Eera natural que admittida a arrojada e animadora conjectura de que estamos destinados à integridade nacional, eu visse naquelles rijos caboclos o nucleo de força da nossa constituição futura, a rocha viva da nossa raça. (ibid: 618) (grifos acrescentados)

Rocha e terra movediça - imagens cartesianas de quase três séculos antes $^{1}$ - parecem apontar não para a força de sua linguagem, o que levou muitos a reputarem sua narrativa como literária, mas principalmente para a angústia de quem vê ameaçada a ordem regente de um mundo tão matematicamente estruturado (vide equação do "salto mortal" com a abertura da citação supra!), que tornaria irrelevante o modelo, o método (que várias vezes o autor propõe abandonar), ou o olhar de quem o percebe.

Note-se também que, se por um lado a certeza sobre a integridade nacional afigura-se-lhe como uma "arrojada e animadora conjectura", por outro lado, o sentimento de menos-valia gerado pelo preço da identificação a uma sub-raça não o abandona. Geracional, tal sentimento promove a encenação em palco local (e as constantes referências ao "amphiteatro" paisagístico confirmam a expectativa do drama) de falas produzidas pelo Velho Mundo. São vendéias,

1. A respeito da dúvida como etapa para certeza, Descartes declara: "não que nisto imitasse os céticos que apenas duvidam por duvidar e afetam ser sempre irresolutos; mas ao contrário, todo o meu intuito era conquistar certeza e rejeitar a terra movediça e a areia para encontrar a rocha e a argila." Discurso do método. Rio de Janeiro: Ed. Ouro, 1960. p. 82. 
chouans, fovilles, turreaus, entre outros, os moldes eurocêntricos reproduzidos por nosso autor como também o são as políticas oficiais de substituição dos contingentes mestiços pelo incentivo à imigração estrangeira nos anos seguintes, como podemos observar Tavares Bastos em Cartas de um Solitário:

é preciso mudar de hábitos, é preciso pôr outra alma no corpo brasileiro. E eu não conheço senão um meio eficaz para isso, a saber: abrir francamente os Portos do Império ao estrangeiro, colocar o Brasil no mais estreito contacto com as raças viris do Norte do Globo, facilitar as comunicações interiores e exteriores, promover a imigração germânica, inglesa e irlandesa, e promulgar leis para a mais plena liberdade religiosa e industrial. (VIANNA, 1991: 370)

Logo, a hereditariedade marcava o homem, seu espaço e seu devir. A essência antecedia a existência - criava-a. Palavra e mundo eram um. A dissonância, o estranhamento, portanto, reiteramos, faz emergir aos olhos de Euclydes a "ficção geographica", definida pela "realidade" das sucessivas derrotas impostas às tropas republicanas, pela inversão radical dos pressupostos de inteligibilidade absoluta do mundo:

\section{Uma ficção geographica}

A linha ferrea corre no lado opposto. Aquelle liame do progresso passa porém, por alli, inutil, sem attenuar sequer o caracter genuinamente roceiro do arraial. Salta-se do trem; transpõe-se poucas centenas de metros entre casas deprimidas; e topa-se para logo, à fimbria da praça - o sertão... Está-se no ponto de tangencia de duas sociedades, de todo alheias uma a outra. (...) (ibid: 520-1) (grifos acrescentados)

\section{Euclydes e o olhar reverso da Favella}

De tanto fingirmos acreditar na ficção da vivência e da razão, acabamos perdendo a fé na realidade. A sensação do absurdo e o cogumelo atômico estão aí para prová-lo.

Flusser, Da ficção

A suspensão do tempo dentro do palco da caatinga dota a narrativa euclidiana em A Lucta de seu sentido trágico. É flagrante o uso dramático do presente simples em toda a subsecção intitulada A guerra das caatingas (CUNHA, 
1933: 238-244) para tal efeito, sobretudo se contrastado com a opção pelo passado simples no relato do ataque de Uauá (ibid: 229-235) um pouco antes. A diferença de tratamento lingüístico da luta sublinha não só o movimento de fluxo e refluxo da escrita de Euclydes em relação aos enunciados iniciais, como já sugerido, mas também a crescente consciência da perda de um lugar privilegiado de enunciação. O presente simples encena a tragédia, traz a agonia inexorável da vida para o momento da fala. O passado simples afasta o drama do momento da enunciação, esvaziando o presente do enunciado distanciado.

Tal dualidade culmina com o deslocamento do exército republicano para o alto da Favella, ponto tal em que podemos definitivamente localizar, senão uma metanarrativa, ao menos a emergência de uma relevante fala de dentro, onde os supostos protagonistas da História se vêem inesperadamente como meros fantoches - objetos do ataque daqueles que estariam predeterminados a cumprirem o que lhes havia reservado a República e as "formas mais avançadas de pensamento." Como usada por nosso autor, portanto, a invisibilidade bifronte do jagunço sinaliza para a cegueira da República, que, ao produzir o não-cidadão, sofre física e moralmente as conseqüências desta fabricação. Do ponto de vista proporcionado pelo alto da Favella tanto o mundo sensível como o mundo racional mostram suas chagas.

É de lá que literalmente cai por terra a roupagem institucional dos soldados republicanos, muitos dos quais, como o batalhão da Bahia, tão jagunços quanto os jagunços que atacavam. É do alto da Favella que a debilidade dos corpos malnutridos dos conselheiristas, das próprias crianças combatentes e de suas casas de argila se transforma em força. É de lá também que a História aparece "de uma ocular invertida", telegrafada para a imprensa, que, com "alarido falso", ficcionaliza "a realidade no ermo da Favella" (CUNHA, 1933: 475-476). É deste lugar aparentemente privilegiado pela altura que se constata a fragilidade dos atacantes diante dos homens invisiveis. Na verdade, é o primado do olhar (LIMA) que cede lugar ao "indizível, não-boquejado", (CUNHA). Aqui, a audibilidade do sino convocando para as rezas vespertinas $e$ para o combate juntamente com a persistente ladainha das mulheres integra-se a uma rede complexa de novos significados para velhos sinais, atordoando mais do que o revide dos adversários inexplicáveis. Se outrora o testemunho vinha de fora, claro e articulado, agora é invadido por áreas de sombra e luz que nele se alojam, como podemos observar nas trocas entre os soldados entrincheirados: 
A vida normalisara-se naquella anormalidade. Despontavam peripecias extravagantes. Os soldados da linha negra, na tranqueira avançada do cerro, travavam, à vezes, noite velha, longas conversas com os jagunços. O interlocutor da nossa banda subia à berma da trincheira e, voltando para a praça, fazia ao acaso um reclamo qualquer, enunciando um nome vulgar, o primeiro que lhe acudia ao intento, com voz amiga e lhana, como se appelidasse algum velho camarada; e invariavelmente, do amago da casaria ou, de mais perto, de dentro dos entulhos das igrejas, lhe respondiam logo, com a mesma tonalidade mansa, dolorosamente ironica. Entabolava-se o colloquio original atravéz das sombras, num reciprocar de informações sobre tudo, do nome de baptismo, ao logar do nascimento, à familia e às condições da vida. Não raro a palestra singular derivava a cousas escabrosa-mente jocosas e pelas linhas proximas, no escuro, ia rolando um cascalhar de risos abafados. (ibid: 547) (grifos acrescentados)

O aparente mistério do "colóquio original através das sombras" que aproxima os "inimigos" insinua uma comunicação incipiente onde a dimensão verdadeiramente humana de ambos rompe as barreiras levantadas por séculos de afastamento forjado politicamente. A compreensão de que as bases sobre as quais tentava-se organizar o poder público eram inteiramente avessas aos ideais pregados pela retórica republicana provoca o lançamento do grito de protesto do autor:

Ademais, não havia temer-se o juízo tremendo do futuro.

A Historia não iria até alli. [...]

O sertão é o homizio. Quem lhe rompe as trilhas, ao divisar à beira da estrada a cruz sobre a cova do assassinado, não indaga do crime. Tira o chapéo e passa.

E lá não chegaria, certo, a correcção dos poderes constituídos. O attentado era publico. Conbecia-o em Monte Santo o principal representante do governo e silenciara. (ibid: 570) (grifos acrescentados)

Curiosa e ironicamente, o que Euclydes julgava ser uma visão de passado incompatível com a modernidade que ele e os de sua geração abraçavam agigantar-se-ia como futuro próximo exatamente a partir da realocação na capital da República dos remanescentes da guerra. Euclydes da Cunha anteviu inversamente a projeção do passado futuro adentro, no sentido em que a alegoria dos parênteses usada para Canudos deixaria de indicar a exceção para padronizar de forma generalizada a teia social da recém-inaugurada República: 
Canudos tinha muito apropriadamente, em roda, uma cercadura de montanhas. Era um parenthesis; era um hiatus. Era um vacuo. Não existia. Transposto aquelle cordão de serras, ninguem mais peccava.

Realisava-se um recúo prodigioso no tempo; um resvalar estonteador por alguns seculos abaixo.

Descidas as vertentes, em que se entalava aquella furna enorme, podia representar-se lá dentro, obscuramente, um drama sanguinolento da Edade das cavernas. (ibid: 570) (grifos acrescentados)

Se aquela "cidadella-mundeo" desaparecia sob escombros produzidos pela "força civilizatória", esta mesma força encarregar-se-ia de manter condições para a ininterrupta reedição de tais células urbanas e tais relações sociais. São mais de 600 as unidades faveladas só na ex-capital federal em cem anos de Canudos.

Um detalhe no próprio grafismo da escrita arremata formalmente o estranhamento produzido pelo empreendimento euclideano: "O fim" - subtítulo de uma das últimas seções da obra - e o FIM propriamente dito - clichê de fechamento, fora do corpo imediatamente posterior ao último comentário intitulado "Duas linhas". Reproduzamo-los:

\section{O fim}

Não ha relatar o que houve a 3 e a 4.

A lucta, que viera perdendo dia a dia o caracter militar, degenerou, ao cabo, inteiramente. Foram-se os ultimos traços de um formalismo inutil: deliberações de commando, movimentos combinados, distribuição de forças, os mesmos toques de cornetas, e por fim a propria hierarchia, já materialmente extincta num exercito sem distinctivos e sem fardas ( ibid: 610) (grifos acrescentados)

O relatório, o formalismo e a própria língua perdem seu poder de apresentação de um mundo que zomba dos meios de acesso a ele, que se impõe a nós pela esguelha da representação. Será para o autor o fim da ilusão sobre o saber não mediado? Sobre os limites de cada e toda testemunha para quem a traição se impõe como único e último recurso de tanger o mundo? Eloqüente também é a forma como uma narrativa tão minuciosa e extensa resultante de uma crença na palavra, no verbo e sobretudo nos nomes como substitutos de mundo, é tomada por sintomas de afasia, terminando reticente como um afterthought: 
Disponivel em: http://www.letras.ufmg.br/poslit

\section{Duas linhas}

É que ainda não existe um Maudsley para as loucuras e os crimes das nacionalidades... *

FIM (ibid: 614)

O comentário final, inconcluso pelas reticências, portador de uma nota de rodapé, segue a crítica feita à exibição da cabeça de Antonio Conselheiro na capital federal para "multidões delirantes", para que "a sciencia dissesse a ultima palavra" sobre o crime e a loucura (ibid: 613). A ponte feita por Euclydes na nota de rodapé entre a impossibilidade de se traçar uma linha ideal entre o bom senso e a insânia, segundo Maudsley, e os crimes e as loucuras da nacionalidade joga a pá de cal nos objetivos primeiros do "projeto Os Sertões" como instrumento de definição de Brasil divorciado dos lugares de enunciação. A miscigenação como metáfora para o novo nascido do encontro dos diferentes ainda busca, um século depois, um lugar na República que a realize como projeto civilizatório, pelo qual natureza seja simplesmente um vácuo, uma ficção passível de investimentos por práticas culturais, institucionais e políticas que cada vez mais garantam o alargamento da cidadania, deixando à mostra o esgarçamento da Razão.

\section{Guerra de Canudos - condições da tradução cinética de Os Sertôes}

Com um gesto sobressaltado, virei para trás e tudo o que vi foi o espelho oval na parede. O vidro devolveu o meu sorriso meio sem graça, em face do meu próprio ridículo. Mas nesse momento, com a sensação de que o espaço da sala havia encolbido, pressenti que ele estava ali, ocultando-se habilmente na faixa estreita onde o foco dos meus olbos e o raio do reflexo do espelbo não podiam alcançá-lo. Rubens Figueiredo. Os distraidos.

Ensejado pela comemoração do centenário em 1997 da dizimação do arraial de Canudos, o projeto cinematográfico Guerra de Canudos de Sergio Rezende detém o inegável mérito de promover "lugares de memória", na expressão de Pierre Nora, em um território onde, cem anos decorridos do 
testemunho de Euclydes, o acesso à leitura, às salas cinematográficas ou ao teatro é, para a maior parte da população, muito mais que restrito - é vetado. Se tal apartheid se dá apesar ou em razão desta "unificação nacional" nos interessa somente na medida em que possamos aferir a experiência derivada dos media que fazem circular as representações sociais de nós mesmos. As condições econômicas que norteiam a produção de filmes "nacionais", seu diálogo com demandas mercadológicas transnacionais, e sobretudo as condições de circulação e recepção da "mercadoria cinematográfica" dentro do Brasil nos parecem relevantes para politizar a discussão, colocando o quadro contextual e o histórico em diálogo com a composição interna, propriamente estética da obra.

Comecemos por examinar alguns dos índices relativos ao acesso da população aos produtos da indústria cultural cinematográfica na atualidade. Em artigo intitulado "O Brasil precisa se ver", Nelson Hoineff declara:

Um estudo recentemente produzido por William G. Lopes Saab e Rodrigo M. Ribeiro para o BNDES mostra a evolução do número de salas de cinemas no Brasil - de 1301 em 1998 para 1525 em 2000 (nos Estados Unidos, a título de comparação, são mais de 35 mil salas). Ainda assim, o Brasil tem hoje uma sala de cinema para cada 119.429 habitantes - quatro vezes menos do que seria considerado ideal. No ano passado, foram vendidos cerca de 80 milhões de ingressos no país. Esses ingressos foram comprados por cerca de 10 milhões de pessoas, que foram ao cinema uma média de oito vezes ao ano. Isso que dizer que 93\% da população brasileira simplesmente não entraram numa sala de projeção. (grifos acrescentados)

Se ao lado destes números colocarmos os relativos ao consumo de livros, amplamente divulgados pela imprensa por ocasião da Bienal do Livro no Rio de Janeiro em meados de 2001, facilmente salta aos olhos a amplitude de tal inacesso:

Num país em que cada pessoa compra em média 0,9 livro por ano (tirando os didáticos) é realmente de espantar que mais de 450 mil pessoas sejam esperadas num evento em que devem ser lançados cerca de 1200 títulos novos. (...)

'A multiplicação de títulos não é necessariamente uma indicação de saúde editorial' (...) 'Em toda parte do mundo, e creio que o Brasil não seja exceção, tem sido observada uma redução das compras de livros pelos leitores. Não uma redução do total de livros vendidos, mas da porcentagem 
de exemplares por leitor", esclarece. (...)

Segundo Chartier, o fenômeno demonstra uma transferência dos gastos dessa parcela da sociedade para outras atividades culturais, como a música, o cinema, o teatro, o turismo e a internet. A resposta dos editores tem sido a multiplicação dos títulos, de forma a atrair a atenção dos leitores para algum tema ou autor e, assim, compensar as perdas com a queda do número médio de exemplares vendidos por título. (COSTA, Cristiane. Livros demais, leitores de menos. ( Jornal do Brasil. Idéias. Livros. p.1) (grifos acrescentados)

A restrição que talvez ainda pudesse ser feita às observações de Chartier acima é que se o "fenômeno da transferência" da leitura para outros produtos culturais é observável globalmente, no Brasil o problema ganha colorações bem particulares pois, como observado nos dados disponibilizados por Hoineff, podemos perceber que não há uma rede nacional de distribuição de produtos culturais, nem nunca houve, padecendo o teatro e o cinema também dos mesmos males de distribuição que afetam o mercado livreiro. Pertinente, portanto, a observação de José Murilo de Carvalho (1999) sobre o sentido do moderno dado ao aristocrático quando da virada do Brasil imperial para o século XX republicano. Então, como agora, a visibilização do excesso trazida pela concentração dos signos do moderno nos centros sempre privilegiados e nas mãos de poucos criava a ideologia do acesso universal a eles, ilusão, como vimos na discussão de Os Sertões, "honestamente" defendida por muitos de seus arautos.

Segue-se, pois, que falar do boom do cinema nacional experimentado mais acentuadamente a partir da segunda metade da década de 90 requer extrema cautela para situá-lo diante do descompasso acima e das aceleradas transformações que atingiram em cheio diversas esferas de nossa vida pública e privada. Em primeiro lugar, o próprio enfraquecimento de signo nacional demanda manter no horizonte as parcerias com o estrangeiro, as pressões exercidas por fundos, bancos e outras ordens monetárias hegemônicas que subordinam certas particularidades a outras. Atentemos para o fato de que o agendamento, o olhar e o espetáculo - que cunha representações do nacional e do local, do estranbo- já os fazem nascer como "mercadorias culturais" produzidas por interesses que as querem veiculáveis em circuito planetário. 


\section{Guerra de Canudos e Euclydes - entre o narrador e a personagem}

Como procuramos enfatizar na primeira parte deste trabalho, é a expressão do conflito entre testemunhar e narrar em Euclydes que promove a fantasmagoria de signos que se desfazem e se confundem todo o tempo. Diante de tais considerações, julgamos ser útil começar a discussão do filme de Sergio Rezende pela personagem vivida pelo fotógrafo/repórter, cuja inserção parece deslocar para o exterior, para o confronto entre reportagem jornalística (isenta, total) e história oficial (interessada, fragmentada), o drama vivido internamente pelo autor de Os Sertões.

No filme, o repórter é, de fato, uma figura desproblematizada, avizinhando-se sua caracterização mais do plano do que da multifacetação. A instituição militar se interpõe ao seu trabalho jornalístico comprometido com a divulgação dos "fatos" da Campanha - existe um lugar da verdade fora da história oficial, que reside na lente e na pena do fotógrafo/repórter, extensivo à câmera do cineasta "objetivada" por sua invisibilização. Por isto mesmo, esta personagem é destituída de intensidade dramática, sendo sua função na narrativa a de veicular frases e textos do original euclideano "explicando" o malogro republicano. De uma certa forma, a personagem Luisa encena com muito mais complexidade o embate entre os lados opostos do combate, em uma trajetória que a desloca da "barbárie" conselheirista para a "civilização" republicana. A solução iconográfica para a "fraternidade" ameaçada é obtida pela foto das duas irmãs, que desbota na medida em que suas vidas passam a representar a própria nação cindida pelos poderes recém-instituídos. O fechamento do filme, no entanto, devolve ao discurso verbal nas falas de Luisa o primado da expressão da verdade sobre a República, desinteressando-se das questões inconclusas a respeito do arraial de Belomonte e da figura do Conselheiro. Espectadores, somos seqüestrados pela tomada frontal da personagem-testemunha que a nós se dirige para testemunharmos de dentro a verdade inequívoca diante da câmera invisível.

Se é plausível falarmos do esvaziamento dramático da personagemnarradora do livro para o filme, a manutenção da atmosfera "inumana" que envolve o Conselheiro, contrariamente, transfere do livro para o filme uma zona de interdito que reduz a relação de Antonio Maciel com seus seguidores à de mera ascendência espiritual do primeiro sobre os últimos. Certamente, a introdução dos conflitos no seio da família Lucena - desde o momento da fuga 
de Luisa à expressão de dúvida de sua mãe sobre as determinações do chefe espiritual - dota a produção cinética de nuances sobre a vida íntima dos conselheiristas invisíveis à pena de Euclydes. Concessões feitas por este aos "antecedentes históricos" de Antonio Maciel, com a rendição da crônica de sua família, ou ao cotidiano dos conselheiristas inferido pelo "passeio por dentro de Canudos" se provam insuficientes para legitimar a fala do Outro diante do autor de Os Sertões. Se no livro aquele é inventado como "grande homem pelo avesso", no filme sua grandeza se reveste de propriedade quase divina na transcrição da cena em que, envolto por uma iluminação ambígua e enfumaçada, a figura trôpega de Antonio Maciel paralisa o soldado republicano que o tem como alvo certo. Sobre as prédicas de Antonio Conselheiro, caracterizadas por Euclydes como "oratória bárbara e arrepiadora", sobre Canudos como uma urbs homogênea e igualitária ou Antonio Conselheiro e seus seguidores como "bruxas, orangotangos ou titãs" (CUNHA), adverte-nos Rogério Souza Silva contra a despolitização de nosso entendimento sobre nós mesmos; subtraída a fala própria, sempre incerta e contraditória, nos restam representações animalescas ou sobrehumanas, perpetuando, do século XIX ao XXI, "guerras particulares fora da pátria".

Neste sentido, ao contrário do papel reservado às mulheres sertanejas em Os Sertões (HERMANN: 245), as personagens femininas em Guerra de Canudos são as que mais fortemente dinamizam a narrativa, complexificando por sua percepção de mundo os dois lados do combate. Se a prostituição de Luisa pode à primeira vista inseri-la dentro de estereótipos da vítima, por outro lado não the retira a regência de suas relações com os homens. Ela desafia o Conselheiro e o pai na fuga e no reencontro, empurra o marido para o campo de batalha, mata o amante republicano e salva a irmã Tereza dos escombros do arraial, para acabarem, na cena final, rezando não o Pai Nosso mas a mesma Ave-Maria que aturdia Euclydes ao final de cada tarde ao alto da Favella. Como mencionado acima, é também a mãe de Luisa que se pronuncia sobre as incertezas do projeto conselheirista, justificando sua adesão a ele mais pela crença que tivesse garantida sua "propriedade particular" do que propriamente por um engajamento ideológico a uma causa comunitária e/ou religiosa. Uma concessão ao gênero ou o descentramento de falas totalizantes, qualquer que seja o caso, a opção de Sergio Rezende parece-nos louvável pelo quanto se aproxima neste momento específico do problema geral inclusão/exclusão pela inserção do particular feminino/masculino.

Finalmente, se em Os Sertôes o modelo de verdade passa pela forja evolucionista e dita o discurso racista que permeia toda a obra, em Guerra de 
Canudos desaparecem por completo quaisquer referências ou alusões aos códigos geneticistas que marcavam o corpo (e a alma) do brasileiro nos legando até hoje um estigma centenário; no filme, o conflito entre atraso e progresso se sustenta muito mais pela leitura dicotômica de campo e cidade, como em Noventa e Três, de Victor Hugo. Como aponta a historiadora Jacqueline Hermann, "o filme acaba aumentando a distância que ainda nos separa da forma como aquele grupo entendeu o mundo que o cercava, reforçando estereótipos que foram construídos em momentos específicos da construção da própria história de Canudos." (HERMANN, 2001: 242).

Acrescentamos que deixar de falar de racismo no Brasil em 1997 parece apontar muito menos para uma leitura cinematográfica independente da obra euclidiana do que para a produção de um esquecimento sobre a história de nossas relações sociais. Deslocada a causa de nossas mazelas para questões de caráter estritamente econômico, ficam silenciadas as questões que nos assombram exatamente hoje como há cem anos, embora circulando de forma oposta nos meios de comunicação de massa, especialmente no televisivo.

\section{Guerra de Canudos como documentário na década de 90}

A propósito mesmo da pouca expressividade dos movimentos de câmera e do reduzido número de ângulos, Guerra de Canudos parece engordar o rol de um cinema que pouco evidencia os recursos que lhe são próprios, adotando, como sói acontecer sobretudo aos filmes "históricos", uma narrativa mais acentuadamente verbal do que propriamente cinética. Predominam os "American shots" (tomadas da cintura para cima) - paradigma televisivo instaurador de um "cinema-verdade", que em três décadas de exibição no Brasil vem unindo o noticiário de TV, os programas de auditório, as novelas e ultimamente os "reality shows" dentro de uma mesma enunciação. O que se pretende sugerir é que a "ausência" da câmera dentro da narrativa cinematográfica acaba reforçando a valorização de um "copismo", para usar o termo euclidiano, que garante o enunciado da verdade em si independentemente do sujeito que a enuncia. 


\title{
Considerações finais
}

Separados por um século de histórias, encontramos em Os Sertões e Guerra de Canudos experiências da "verdade" sobre o Brasil e sobre os brasileiros situadas em um lugar fora da fala que parece, ao elidir os meios de tradução textual, isentar o sujeito da enunciação de seus enunciados, eternizando estes. A primeira obra é permeada, no entanto, por um estranhamento de seu narrador na relação com o Outro que o torna personagem central no drama de definir o Brasil. A segunda obra exila o narrador e resgata a testemunha ocular "isenta”, sem impressões digitais, eliminando o caráter fantasmático encontrado no primeiro e sugerindo novas "descobertas" do Brasil. Uma tendência mais auto-reflexiva identificável não só mas em boa parte dos documentários da década de 90 desestabiliza a própria definição de documentário e de "verdade", deslocando no making of a centralidade da narrativa para o narrador $\mathrm{e}$ implicando o espectador em uma relação de cumplicidade com o narrador ambos simultaneamente sujeitos e objetos da história que tecem. Terra movediça e rocha viva permanecem figuras atuais para não mais descrever o progresso da razão rumo à plenitude dos tempos e das narrativas, mas para sinalizar o caráter traiçoeiro de todo e qualquer meio narrativo.

\begin{abstract}
This discussion dwells on the narrator as a translator of alterities within an ideal of nation and of republic in Brazil. Os Sertões by Euclydes da Cunha (1902) and Guerra de Canudos by Sergio Rezende (1997) comprise the corpus where the status of truth, of the original and of the means of translation are analyzed as producers of meaning and of betrayal. The testimonial genre is questioned in its ideological nature both in sociological discourses as models for the world and in fictional and/or cinetic adaptations.
\end{abstract}

Keys-words: translator, nation, alterities. 
Disponivel em: http://www.letras.ufmg.br/poslit

$$
\text { Referências Bibliográficas }
$$

BENJAMIN, Walter. Magia e técnica, arte e política: ensaios sobre literatura e história da cultura/ Walter Benjamin. Trad. Sergio Paulo Rouanet. São Paulo: Brasiliense, 1994.

CARVAlHo, José Murilo de. Pontos e bordados: escritos de história e de política. Belo Horizonte: Ed. UFMG, 1999.

COSTA, Cristiane. Livros demais, leitores de menos. Jornal do Brasil, Rio de Janeiro, 12 mai. 2001, JB Idéias, Livros, p. 1

CUNHA, Euclydes. Os sertões: campanha de Canudos. 12. ed. Rio de Janeiro: Francisco Alves, 1933.

FREUD, Sigmund. O estranho. In: Obras completas. v. 17. Rio de Janeiro: Imago, [s.d.].

HERMANN, Jacqueline. Imagens de Canudos. In: SOARES, Mariza de Carvalho e FERREIRA, Jorge. A bistória vai ao cinema. Rio de Janeiro: Record, 2001.

HOINEFF, Nelson. O Brasil precisa se ver. Jornal do Brasil, Rio de Janeiro, 22 jan. 2002, p. 9.

LIMA, Luiz Costa. Nos sertões da oculta mimesis. In: O controle do imaginário: razão e imaginação nos tempos modernos. 2. ed. cap. 4. Rio de Janeiro: Forense Universitária, 1989.

LUKÁCS, G. Narrar ou descrever? [s.l.]: [s.n.], [s.d.].

RIBEIRO, Renato Janine. A política como espetáculo. In: DAGNINO, Evelina (Org.). Os anos 90: política e sociedade no Brasil. São Paulo: Brasiliense, 1994. p. 31-40.

SILVA, Rogério Souza. Antônio Conselheiro: a fronteira entre a civilização e a barbárie. São Paulo: Annablume, 2001.

VIANNA, Luiz Werneck. Americanistas e iberistas: a polêmica de Oliveira Vianna com Tavares Bastos. In: MORAES, João Quartim de e BASTOS, Élide (Org.). O pensamento de Oliveira Vianna. [s.l.]: [s.n.], [s.d.]. 